\title{
The Effect of in Water Selective Exercises on Muscle Strength in Patients with Muscle Dystrophy
}

\author{
Aliakbar Najafvand Derikvandi ${ }^{1} \&$ Rezvan Kaviyaniniya ${ }^{1}$ \\ ${ }^{1}$ M.Sc. Sports Pathology, Islamic Azad University, Boroojerd Branch, Boroojerd, Iran \\ Correspondence: Aliakbar Najafvand Derikvandi, Islamic Azad University, Boroojerd Branch, Boroojerd, Iran. \\ Tel: 98-66123253.
}

Received: February 20, 2017 Accepted: June 25, 2017 Online Published: June 30, 2017

doi:10.5539/gjhs.v9n8p148 URL: https://doi.org/10.5539/gjhs.v9n8p148

\begin{abstract}
Muscular dystrophy syndrome refers to a group of genetic diseases resulting in muscle weakness and low functional capacity. This purpose of this study is to investigate the effect of an eight-week selective training on muscle strength of patients with muscular dystrophy. A quasi-experimental method was used in this study. Eleven patients with muscular dystrophy were selected through purposive sampling and divided into two groups randomly including in water selective exercises $(n=6)$ and control groups $(n=5)$ respectively. The study conducted under the supervision of researcher for eight weeks, three sessions per week, and the time allocated was between 60-45 minutes. Moreover, a t-test was used for statistical analysis and the significant level was set at $\mathrm{p}<0.05$ level. After an eight-week training a significant increase $(\mathrm{P}<0.05)$ was observed in extensor muscle strength in patients with muscular dystrophy. However, no significant difference was observed in the control group ( $p \geq 0.05)$. Comparing the changes made during eight weeks (difference between pre-test and post-test) a significant difference $(\mathrm{P}<0.05)$ was observed between intervention and control groups. According to obtained findings in this study, in water selective exercise is an effective way to improve muscular strength in patients with muscular dystrophy.
\end{abstract}

Keywords: muscular dystrophy, muscle strength, in water exercise

\section{Introduction}

A wide range of diseases includes those with hereditary neuromuscular deficiencies. Their main features are muscle weakness and muscle assimilates. These diseases are categorized into different types such as Duchene, Fasoakapolohomral, and Limb-girdle muscular dystrophy in terms of their location, muscular weakness and inheritance pattern. Congenital muscular dystrophies, Duchene Dystrophynopaty and Becker are common types of these diseases. Muscular dystrophies are caused by defects in the cell membrane. Defect appears clearly in the sarcolemma. Cells are connected to each other through a set of (complex) massive protein in the muscle tissue, and defects in any component of this complex leads to a kind of dystrophy (Adams, 1975).

One of the main problems of patients with dystrophy is low functional capacity (Johansen, 2003). In this regard, Sockolov et al. collaborate on research to determine the effect of dystrophy on dynamic athletic performance, cardiovascular response to incremental exercise and isokinetic strength of organs. Sockolov et al. have compared 13 11-6-year-old boy with dystrophy and 13 6-11-year-old non-athletes boy. The findings indicate a lower than normal level indicators measured in boys with dystrophy (Sockolov, Irwin, Dressendorfer, \& Bernauer, 1977).

Muscular dystrophy includes a wide range of disabilities and medical problems in adults that need to be timely diagnosis and management. Weight control and orthotics use can make some things practicable as much as possible for patients. Taking into account the severity and progression of the disease, the patient may require surgery. Patients' main issues such as employment, personal relationships, sex, parents, and chronic disability, need clear analysis and sympathetic management. After that, respiratory failure is of considerable reservations . Studies have shown that muscular dystrophy causes muscle atrophy and progressive neuromuscular disorders in patients that could affect their respiratory and cardiovascular function, reduce their quality of life and physical function (Edwards, 1989). Although no certain cure has been found for the treatment of muscular dystrophy up to now, but medical intervention is needed to alleviate some of the problems caused by dystrophy and improve the patients' quality of life.

Vignos et al. (1996) Conducted a study in line with the effect of exercise on physical function in patients with 
dystrophy in which twenty-four patients with muscular dystrophy were controlled under a resistance-training program for a year. Muscle strength progressed in all patients during the first four months of training regardless of the type of dystrophy. After that, the plateau occurred and did not change during the intervention period. Increasing muscle performance was associated with the initial level of muscle strength as measuring documents. In functional ability, improvement was less than the increase in muscle strength. Patients with shoulder girdle dystrophy and Fasioeskapohomral dystrophy had the most physical and performance benefits from the program (Vignos, 1966). Muscular dystrophy treatment goals include improving long-term outcomes, longevity, and quality of life in these patients (Edwards, 1989). Given the role of muscle strength, endurance in patients' performance and also improve the quality of these people, there is the need for medical intervention to improve physical function in this patient (Vignos \& Watkins, 1966). Experts have noted that moderate-intensity exercise is a safe way to improve physical function in patients with dystrophy (Vignos, Spencer, \& Archibald, 1963). Considering the state of muscular dystrophy patients, these patients may have problems in the exercise on land (Berthelsen, Husu, Christensen, Prahm, Vissing, \& Jensen, 2014). It seems that in water exercises is effective for these patients. This study was designed to investigate the effect of in water eight-week training on muscle strength in patients with muscular dystrophy.

\section{Method}

\subsection{Sample Selection}

A quasi-experimental design was conducted to evaluate the effect of an eight-week in water selective exercises on muscle strength in patients with muscular dystrophy. Eleven volunteered patients with muscle dystrophy were selected. They were randomly assigned into two in water selective exercises $(n=6)$ and control groups $(n=5)$ after signing informed consent by patients and their parents. The control group received no intervention.

\subsection{Measurements}

After measuring the anthropometrics indexes of the patients including standing and sitting height the participants' weight and body mass index and muscle strength were measured. Before performing measurements necessary explanations about how to do it, being comfortable in standing position, looking straight forward, feeling comfortable in standing and equal distribution of weight on both feet were explained to all participants.

Muscle strength of back of the foot was measured using a dynamometer. Participants were placed on the platform of dynamometer device so that the legs were parallel to each other about $15 \mathrm{~cm}$.

Foot should be quite right, dynamometer's handle shoul be hold with hands while both hands have internal rotation. Then testee pull the handle up without deviation toward the rear of the body and use only back muscles. Testee must maintain the starting position at all stages in this test. It means that testee must hold his/her head and foot in vertical position. The amount of measured force in kilograms were recorded for each subject.

\subsection{Exercise Training Program}

The exercise group enrolled in 24 sessions over eight weeks, 3 days a week. The exercise group received necessary explanation about the sport and its benefits. They were under in water selective exercise according to their body condition and muscle weakness.

Warm up: In the present study the warm-up excercises including walking forward, backward, backward and sideways across the pool and body stretching was about 10 minutes in the shallow pool at the beginning of each session.

Special enhancer moves: Enhancer excercises include 15-10 minutes of resistance training exercises were conducted in the pool.

Swimming preliminary exercises: Preliminary exercises were conducted under the supervision of a swimming instructor in the pool for 15-10 minutes in this study. Preliminary exercises and training were performed with the help of another person and aid to maintain buoyancy of subjects because subjects were not familiar with swimming. The swimming training was conducted for 30 periodic seconds and the rest time between periodic rotations was about a minute, but in the case of fatigue more relaxing time was considered..

Cool Down: Cool-down exercise (recovery) was performed by subjects for 5 minutes.

\subsection{Statistical Methods}

Descriptive statistics including mean and standard deviation were used in this study. A paired t-test (t-affiliated) was used to compare the difference between pre-test and post-test variables of the study and an independent t-test was used to compare the mean differences created between experimental and control groups. All statistical 
analyses were performed at the significant at $\mathrm{p}<0.05$ level.

\section{Results}

In Table 1, the results of anthropometric variables descriptive statistics including standing and sitting height, weight, body mass index, breast arch length and age of subjects are expressed in both experimental and control groups.

Table 1. Anthropometric indices in studied groups

\begin{tabular}{lllll}
\hline variables & Age $(\mathrm{y})$ & Height $(\mathrm{cm})$ & Weight $(\mathrm{kg})$ & BMI $(\mathrm{kg} / \mathrm{m} 2)$ \\
\hline Exercise group & $11.83 \pm 1.94$ & $142.10 \pm 9.78$ & $33.07 \pm 5.75$ & $16.26 \pm 1.09$ \\
Control group & $11.60 \pm 1.67$ & $138.04 \pm 8.20$ & $31.96 \pm 5.42$ & $16.68 \pm 1.32$ \\
\hline
\end{tabular}

In examining changes within groups (Table 2) after eight weeks of specific reforms training, strength muscles increased significantly in the experimental group $(\mathrm{P}=0.100)$. However, no significant difference was observed in the control group $(\mathrm{p}<.05)$.

Table 2. Paired sample t-test for pre-intervention and Post-intervention Values of muscle strength

\begin{tabular}{lllll}
\hline Group & Pre- test & Post- test & t & P \\
\hline Exercise group & $12.11 \pm 2.75$ & $16.67 \pm 1.03$ & -12.85 & 0.000 \\
Control group & $13.10 \pm 1.17$ & $12.10 \pm 2.42$ & 0.889 & 0.419 \\
\hline
\end{tabular}

Table 3. Independent t-test for Comparison of Mean differences of investigated variables between exercise and control groups

\begin{tabular}{llll}
\hline Group & Post- test - Pre- test & $\mathrm{t}$ & $\mathrm{P}$ \\
\hline Exercise group & $4.80 \pm 1.10$ & 4.223 & 0.002 \\
\hline Control group & $1.60 \pm 0.50$ & \\
\hline
\end{tabular}

\section{Discussion}

The independent t-test results presented in Table 3, showed a significant difference between the created changes in the spinal extensor muscles strength of in water selective exercises and control groups $(p=0.002)$.

Results have shown that an eight-week in water selective exercises and swimming exercises increase muscle strength in the experimental group. While no significant difference was observed in the control group.

That was in line with Vygnvs et al. (1966) finding which reported muscle strength increase in patients with muscular dystrophy during the four months of training. In addition, Johnson et al. (Johansen, 2003) reported a significant improvement in knee muscle strength in closed kinetic chain after combined antigravity exercises in their study. Alemdaroğlu et al. (2015) have reported a significant improvement in performance indicators as well as muscle strength of patients after a period of eight-week at home training on new patients that were suffered from Duchene disease, which is in line with the current study. Anderson et al (Andersen, 2015) conducted a study an facioscapulohumeral muscular dystrophy reported a significant improvement in muscle strength in patients with facioscapulohumeral muscular dystrophy after 36 sessions of aerobic exercise that was in line with the findings in current study. One of the main problems of patients with Dystrophy is patients' physical function reduction due to muscle atrophy and low muscle strength and endurance (Miscione et al., 2013; Wagner, Lechtzin, \& Judge, 2007). These patients have lower sports and physical performance than healthy people due to decreased muscle mass, muscle atrophy, muscle necrosis, replacement of muscle tissue by fatty and connective tissue. However, rebuild ATP routes are impaired due to the loss of muscle tissue in these people (Strober, 2006; Lavasani, Lu, Peng, Cummins, \& Huard, 2006). The results revealed that a period of in water exercise increases muscle strength in people with muscular dystrophy significantly.Therefore, water provides a unique environment where gravity loads is reduced on the joints while the water provides resistance to movement. In water exercise can play an effective role in improving physical fitness training and rehabilitation of patients due to these characteristics (Foley, Halbert, 
Hewitt, \& Crotty, 2003), that was observed as extensor muscle strength in the present study.

Among possible power increase reasons neuromuscular adaptations that follow the exercise can be noted. The results show that exercise makes agonists muscles more active and can reduce antagonists muscle activity. In total, it can increase willpower (Häkkinen et al., 1998). Research has shown that light resistance exercise can increase muscle strength (Taaffe, Duret, Wheeler, \& Marcus, 1999). Since a part of the exercises was light resistance training in the current study and because in swimming exercises a kind of resistance is created by the water, resistance is created against the muscle. It seems that the low-resistance in exercise cause training adaptations, and increase muscle strength in patients with muscular dystrophy. Overall, the findings suggest that in water exercise plays a positive role in back muscle strength that can help patients with muscular dystrophy and the medical team in controlling and improving complications of patients. Considering that, one of the most important treatment purposes of patients with dystrophy is increasing physical performance and muscle strength. It seems that this style of exercises due to strengthen the extensor muscles of the spine can cause spinal abnormalities improvement and prevention in these patients. Therefore, it has an important role in improving balance in these patients and as treatment; plans can be useful to improve the quality of life in these patients.

\section{Competing Interests Statement}

The authors declare that there are no competing or potential conflicts of interest.

\section{References}

Alemdaroğlu, I., Karaduman, A., Yilmaz, Ö. T., \& Topaloğlu, H. (2015). Different types of upper extremity exercise training in Duchenne muscular dystrophy: effects on functional performance, strength, endurance, and ambulation. Muscle \& nerve, 51(5), 697-705. https://doi.org/10.1002/mus.24451

Andersen, G., Prahm, K. P., Dahlqvist, J. R., Citirak, G., \& Vissing J. (2015). Aerobic training and postexercise protein in facioscapulohumeral muscular dystrophy RCT study. Neurology, 85(5), 396-403. https://doi.org/10.1212/WNL.0000000000001808

Berthelsen, M. P., Husu, E., Christensen, S. B., Prahm, K. P., Vissing, J., \& Jensen, B. R. (2014). Anti-gravity training improves walking capacity and postural balance in patients with muscular dystrophy. Neuromuscular disorders, 24(6), 492-8. https://doi.org/10.1016/j.nmd.2014.03.001

Edwards, R. H. (1989). Management of muscular dystrophy in adults. British medical bulletin, 45(3), 802-18. https://doi.org/10.1093/oxfordjournals.bmb.a072359

Foley, A., Halbert, J., Hewitt, T., \& Crotty, M. (2003). Does hydrotherapy improve strength and physical function in patients with osteoarthritis - a randomised controlled trial comparing a gym based and a hydrotherapy based strengthening programme. Annals of the rheumatic diseases, 62(12), 1162-7. https://doi.org/10.1136/ard.2002.005272

Häkkinen, K., Kallinen, M., Izquierdo, M., Jokelainen, K., Lassila, H., Mälkiä E, ... Kraemer, W. J. (1998). Changes in agonist-antagonist EMG, muscle CSA, and force during strength training in middle-aged and older people. Journal of Applied Physiology, 84(4), 1341-9.

Johansen, K. L., Shubert, T., Doyle, J., Soher, B., Sakkas, G. K., \& Kent-Braun, J. A. (2003). Muscle atrophy in patients receiving hemodialysis, effects on muscle strength, muscle quality. and physical function. Kidney international, 63(1), 291-7. https://doi.org/10.1046/j.1523-1755.2003.00704.x

Lavasani, M., Lu, A., Peng, H., Cummins, J., \& Huard, J. (2006). Nerve growth factor improves the muscle regeneration capacity of muscle stem cells in dystrophic muscle. Human gene therapy, 17(2), 180-92. https://doi.org/10.1089/hum.2006.17.180

Miscione, M. T., Bruno, F., Ripamonti, C., Nervuti, G., Orsini, R., Faldini, C., ... Merlini, L. (2013). Body composition, muscle strength, and physical function of patients with Bethlem myopathy and Ullrich congenital muscular dystrophy. The Scientific World Journal, 2013. https://doi.org/10.1155/2013/152684

Sockolov, R., Irwin, B., Dressendorfer, R., \& Bernauer, E. (1977). Exercise performance in 6-to-11-year-old boys with Duchenne muscular dystrophy. Archives of physical medicine and rehabilitation, 58(5), 195-201.

Strober, J. B. (2006). Therapeutics in duchenne muscular dystrophy. Neuro Rx, 3(2), 225. https://doi.org/10.1016/j.nurx.2006.01.005

Taaffe, D. R., Duret, C., Wheeler, S., \& Marcus, R. (1999). Once - weekly resistance exercise improves muscle strength and neuromuscular performance in older adults. Journal of the American Geriatrics Society, 47(10),1208-14. https://doi.org/10.1111/j.1532-5415.1999.tb05201.x 
Vignos, P. J., \& Watkins, M. P. (1966). The effect of exercise in muscular dystrophy. Jama, 197(11), 843-8. https://doi.org/10.1001/jama.1966.03110110067015

Vignos, P. J., Spencer, G. E., \& Archibald, K. C. (1963). Management of progressive muscular dystrophy of childhood. Jama, 184(2), 89-96. https://doi.org/10.1001/jama.1963.03700150043007

\section{Copyrights}

Copyright for this article is retained by the author(s), with first publication rights granted to the journal.

This is an open-access article distributed under the terms and conditions of the Creative Commons Attribution license (http://creativecommons.org/licenses/by/4.0/). 